\title{
Resistência a Myzus persicae em genótipos de tomateiro com altos teores foliares de aleloquímicos
}

\author{
Alex Antônio da Silva ( $\left.{ }^{1 *}\right)$; Wilson Roberto Maluf ( $\left.{ }^{1}\right)$; Jair Campos Moraes ( $\left.{ }^{2}\right)$; Roberta Alvarenga (2); \\ Eva Maria Rodrigues Costa (') \\ (') Universidade Federal de Lavras (UFLA), Curso de Pós-graduação em Genética e Melhoramento de Plantas, $37200-000$ Lavras \\ (MG), Brasil. \\ (2) (UFLA), Curso de Pós-graduação em Agronomia - Entomologia, 37200-000 Lavras (MG), Brasil. \\ (*) Autor correspondente: alex_antonio7@hotmail.com
}

Recebido: 22/nov./2012. Aceito: 27/maio/2013

\begin{abstract}
Resumo
O objetivo deste trabalho foi avaliar a resistência ao pulgão Myzus persicae em genótipos de tomateiro com altos teores foliares de aleloquímicos. Para tanto, foi realizado um teste de antibiose e dois testes de não preferência, um com pulgões alados e o outro com pulgões ápteros. Os genótipos utilizados foram as linhagens TOM-687 e TOM-688, ricas em acilaçúcares; ZGB-703 e ZGB-704, ricas em zingibereno; BPX-365G-899-07-04-02 e BPX-367E-238-02, ricas em 2-tridecanona; e dois híbridos comerciais usados como testemunhas, Débora Max e Bravo $F_{1}$ que apresentam baixos teores dessas substâncias. Observou-se aumento do período ninfal dos insetos mantidos sobre os genótipos com altos teores de acilaçúcares, e diminuição do período reprodutivo, da longevidade e da produção de ninfas para pulgões mantidos sobre os genótipos com altos teores de acilaçúcares ou 2-tridecanona. Nos testes de não preferência não ocorreram diferenças significativas entre os genótipos. Conclui-se que os genótipos com altos teores de acilaçúcares ou 2-tridecanona possuem resistência do tipo antibiose a M. persicae.
\end{abstract}

Palavras-chave: Solanum lycopersicum, Insecta, melhoramento genético, alomônios.

\section{Resistance to Myzus persicae in tomato genotypes with high levels of foliar allelochemicals}

\section{Abstract}

The objective of this study was to evaluate the levels of resistance to Myzus persicae of tomato genotypes with high leaf levels of three different allelochemicals. Three tests of resistance were performed, one for antibiosis and two for non-preference, one with winged aphids and another with apterous aphids. The tomato genotypes tested were acylsugar-rich lines TOM-687 and TOM-688; zingiberene-rich lines zgb-703 and ZGB-704; 2-tridecanone-rich lines BPX-365G-899-07-04-02 and BPX367E-238-02, and the commercial hybrid checks Debora Max and Bravo $\mathrm{F}_{1}$, both with low contents of all three allelochemicals. There was an increase in the nymphal period of insects raised on the high-acylsugar genotypes, and shorter reproductive period, shorter longevity, and lower nymph production in genotypes with either high-acylsugars or high 2-tridecanone. Nonpreference tests with both winged and apterous aphids indicated non-significant differences among the genotypes tested. The results indicate that genotypes with high contents of either 2-tridecanone or acylsugars possess levels of resistance type antibiosis to $M$. persicae.

Key words: Solanum lycopersicum, Insecta, plant breeding, allomones.

\section{INTRODUÇÃO}

O tomateiro Solanum lycopersicum L., apesar de ser uma das hortaliças mais cultivadas no mundo (Peralta et al., 2005) é uma planta que apresenta ampla gama de problemas fitossanitários (Suinaga et al., 2003). Dentre o complexo de pragas que atacam a cultura, o pulgão Myzus persicae (Sulzer) (Hemiptera: Aphididae) é considerado um inseto-praga importante, pois além de causar danos diretos pela sucçáo de seiva, o que resulta no enrolamento e engorvinhamento de folhas e brotos novos das plantas, também causa danos indiretos pela transmissão de vírus como o vírus do topo amarelo do tomateiro (PYPV), o vírus Y da batata (PVY) e Luteovírus (ANTTONelli et al., 1992).

O controle de pragas na cultura do tomateiro é feito principalmente por meio da pulverização sistemática com inseticidas. Nas épocas mais quentes do ano chegam a ser feitas duas a três pulverizaçóes por semana, o que pode acarretar problemas de resíduos 
nos frutos, intoxicação de trabalhadores, poluição ambiental, além de aumentar os custos de produçáo da cultura (Silva et al., 2009).

Uma das alternativas para a solução de problemas advindos do uso indiscriminado de defensivos agrícolas é o desenvolvimento de cultivares resistentes a insetos-praga (Leite, 2004). Os programas de melhoramento do tomateiro conduzidos no Brasil têm adotado a estratégia da introgressáo de alelos de resistência a insetos, presentes em espécies silvestres de tomateiro, em linhagens melhoradas com boas características agronômicas (SILVA et al., 2009).

No processo de obtenção de cultivares resistentes é importante o estudo dos tipos e das causas da resistência. Existem três tipos de resistência: antibiose, não preferência e tolerância (Panda e Krush, 1995), sendo os dois primeiros já detectados em espécies de tomateiro. As causas da resistência podem ser tricomas glandulares (efeito de compostos químicos) e não glandulares (efeito mecânico) e as associadas com lamela média, folhas e frutos (Leite, 2004).

Genótipos de tomateiro com altos teores de aleloquímicos nas folhas, que em alguns casos estão presentes em tricomas foliares, foram desenvolvidos em programas de melhoramento pelo cruzamento interespecífico do tomateiro domesticado com espécies silvestres, entre elas $S$. pennelii que produz acilaçúcares (GOFFreda et al., 1989; Resende et al., 2002; 2006), S. habrochaites var. hirsutum que produz substâncias químicas do grupo dos sesquiterpenos, como o zingibereno (CARTER et al., 1988; Gianfagna et al., 1992; Maluf et al., 2001; Freitas et al., 2002), e também com a espécie $S$. harbrochaites var. glabratum que produz a metil-cetona, 2-tridecanona (Juvick et al., 1988; Gonçalves et al., 1998; Aragấo et al., 2000). Esses genótipos são resistentes à mosca branca Bemisia tabaci biótipo b (Hemiptera: Aleyrodidae) (Resende et al., 2009; Silva et al., 2009; Maluf et al., 2010), à traça Tuta absoluta (Lepidoptera: Gelechiidae) (Azevedo et al., 2003; Pereira et al., 2008; Gonçalves Neto et al., 2010), e aos ácaros Tetranychus urticae e T. evanci (Acari: Tetranychidae) (GonçALVES et al., 2006; Maluf et al., 2007). Contudo, sua resistência a afídeos ainda não foi testada.

O objetivo deste trabalho foi avaliar a resistência ao pulgão $M$. persicae em genótipos de tomateiro com diferentes níveis de aleloquímicos (acilaçúcares, zingibereno ou 2-tridecanona) nas folhas.

\section{MATERIAL E MÉTODOS}

\section{Genótipos de tomateiro}

Os genótipos de tomateiro que foram utilizados estão listados na tabela 1. Os genótipos 'TOM-687' e 'TOM-688' são linhagens que possuem altos teores de
Tabela 1. Descrição dos genótipos avaliados para resistência a Myzus persicae

\begin{tabular}{|lc}
\hline $\begin{array}{l}\text { Genótipos/Tratamentos } \\
\text { TOM-687 }\end{array}$ & $\begin{array}{c}\text { Descrição } \\
\text { Linhagem pré-comercial com alto } \\
\text { teor de AA }\end{array}$ \\
\hline ZGB-703 & $\begin{array}{c}\text { Linhagem pré-comercial com alto } \\
\text { teor de AA }\end{array}$ \\
\hline ZGB-704 & $\begin{array}{c}\text { Linhagem pré-comercial com alto } \\
\text { teor de ZGB }\end{array}$ \\
\hline BPX-365G-899-07-04-02 & $\begin{array}{c}\text { Linhagem pré-comercial com alto } \\
\text { teor de ZGB }\end{array}$ \\
\hline BPX-367E-238-02 & $\begin{array}{l}\text { Linhagem com alto teor de 2-TD } \\
\text { Linhagem com alto teor de 2-TD }\end{array}$ \\
\hline DÉBORA MAX & $\begin{array}{l}\text { Híbrido comercial (testemunha), } \\
\text { baixo teor de AA, ZGB e/ou 2-TD } \\
\text { Híbrido comercial (testemunha), } \\
\text { baixo teor de AA, ZGB e/ou 2-TD }\end{array}$ \\
\hline BRAVO F
\end{tabular}

AA: acilaçúcar; ZGB: zingibereno; 2-TD: 2-tridecanona.

acilaçúcares, obtidas a partir do cruzamento interespecífico S. lycopersicum x S. pennellii 'LA-716', seguido por três retrocruzamentos com S. lycopersicum, e selecionadas com base no seu alto teor de acilaçúcares (Pereira et al., 2008; Resende et al., 2009; Gonçalves Neto et al., 2010), seguindo metodologia proposta por RESENDE et al. (2002). Os genótipos 'ZGB-703' e 'ZGB-704' são linhagens que possuem altos teores de zingibereno, obtidas do cruzamento interespecífico S. lycopersicum x S. habrochaites var. hirsutum 'PI-127826', seguido por dois retrocruzamentos para S. lycopersicum, também selecionadas com base no seu alto teor do respectivo aleloquímico (Maluf et al., 2001; Freitas et al., 2002; Azevedo et al., 2003; Gonçalves et al., 2006). Os genótipos 'BPX-365G-899-07-04-02' e 'BPX-367E-238-02' são linhagens com alto teor presumido do aleloquímico 2-tridecanona, selecionados com base em sua alta densidade de tricomas glandulares (Maluf et al., 2007), obtidas do cruzamento interespecífico S. lycopersicum com S. habrochaites var. glabatrum 'PI-134417' seguido por retrocruzamentos com S. lycopersicum. Os híbridos Débora Max e Bravo $\mathrm{F}_{1}$, com baixos teores dos aleloquímicos foram utilizados como testemunhas comerciais.

Os genótipos foram semeados em bandeja de poliestireno expandido com 128 células, previamente enchidas com o substrato comercial Tropstrato HA. No estádio de quatro a cinco folhas definitivas, em casa de vegetação, as mudas foram transplantadas para vasos de polietileno com capacidade para $2 \mathrm{~L}$ de substrato, o qual foi composto de terra de barranco e esterco de curral curtido na proporção $3: 1$. Os demais tratos culturais foram realizados conforme os preconizados para a cultura do tomateiro (Filgueira, 2004).

\section{Criação de Myzus persicae}

Os pulgões foram colocados em placas de Petri de $20 \mathrm{~cm}$ de diâmetro, contendo folíolos de tomateiro 
da cultivar 'Santa Clara', padrão de suscetibilidade a insetos-praga (LeITE et al., 1999b), fixados sobre uma camada de ágar a $1 \%$. As placas foram fechadas com tecido fino voile, viradas para baixo e mantidas em câmara climatizada regulada com temperatura de $25 \pm 2{ }^{\circ} \mathrm{C}$ e fotofase de 12 horas. A cada quatro dias, os pulgões foram transferidos para placas com folíolos novos.

Para a obtenção de pulgóes alados, os insetos criados sobre as folhas de tomate foram transferidos com o auxílio de um pincel para plantas de Nicandra physaloides, aumentando a densidade de pulgóes/planta que foram mantidas em gaiola de acrílico $(1,5 \times 1,0 \times 0,5 \mathrm{~m}) \mathrm{em}$ sala climatizada do laboratório regulada com temperatura de $25 \pm 2{ }^{\circ} \mathrm{C}$ e fotofase de 12 horas.

\section{Teste de biologia}

No estádio do início do florescimento das plantas, os folíolos dos genótipos foram fixados com a parte adaxial voltada para cima em uma lâmina de água/ágar a 1\%, em placas de Petri de $10 \mathrm{~cm}$ de diâmetro. Três fêmeas adultas ápteras, no início do período reprodutivo, retiradas da criação de manutenção, foram transferidas para as placas com um folíolo correspondente a cada tratamento.

Decorridas 24 horas da infestaçáo com pulgóes adultos, estes foram removidos, deixando-se três ninfas de $1^{\circ}$ instar por placa para as seguintes avaliaçôes: duração dos períodos ninfal, reprodutivo, pós-reprodutivo, longevidade, viabilidade ninfal e número médio total de ninfas/fêmea.

As placas foram vedadas com filme de PVC perfurado com alfinete, para evitar umidade excessiva no interior e mantidas em câmara climatizada a $25 \pm 2{ }^{\circ} \mathrm{C}$, umidade relativa (UR) de $70 \%$ e fotofase de 12 horas. O ensaio foi montado em delineamento inteiramente ao acaso, com oito tratamentos (genótipos) e dez repetiçóes, sendo uma placa por repetiçấo. Os folíolos foram trocados a cada quatro dias.

\section{Teste de não preferência com chance de escolha para pulgões alados}

A seleção do hospedeiro assim que os pulgôes chegam à área é realizada pelos pulgóes alados, por isso é importante prever o seu início. Para tanto, vasos com uma planta correspondente a cada genótipo foram dispostos sobre bancadas da sala climatizada, do tipo Fitotron do laboratório, regulada com temperatura $25 \pm 2{ }^{\circ} \mathrm{C}$ e fotofase de 12 horas. No estádio do início do florescimento das plantas, com o auxílio de um sugador entomológico, aproximadamente 300 pulgóes alados, oriundos da criação de manutenção em plantas de $N$. physaloides, foram liberados aleatoriamente no interior da sala climatizada, colocando-se tubos de ensaio contendo aproximadamente 15 pulgóes alados sobre as bancadas, entre os vasos. Após 24 horas da liberação, os tubos foram retirados das bancadas. $\mathrm{O}$ ensaio foi montado em delineamento inteiramente ao acaso, com oito tratamentos e sete repetiçóes, sendo cada repetição constituída por um vaso acima descrito.

Após 72 horas da liberação dos pulgóes foi feita a avaliação por meio da contagem do número de pulgóes, adultos alados e ninfas presentes em cada planta.

\section{Teste de não preferência com chance de escolha para pulgão áptero}

Quando os pulgôes já estấo instalados na cultura é importante prever a movimentação dos pulgões ápteros. Para tanto, no estádio do início do desenvolvimento das plantas, em casa de vegetaçáo, um folíolo do terço médio superior das plantas por vaso foi destacado com o auxílio de uma tesoura e colocado em saco de papel com a identificação do tratamento e repetição correspondente. No laboratório, estes folíolos foram fixados em placas de Petri de $20 \mathrm{~cm}$ de diâmetro, com a face adaxial voltada para cima, sobre uma camada de ágar a $1 \%$ e cobertos com um filme de PVC perfurado, com auxílio de um alfinete entomológico. Cada placa recebeu um folíolo de cada um dos oito tratamentos, dispostos em círculo, equidistantes entre si, formando uma arena. No centro de cada placa foram liberados 24 pulgóes adultos ápteros no início do período reprodutivo. As placas foram mantidas em câmara climatizada do laboratório regulada com temperatura de $25 \pm 2{ }^{\circ} \mathrm{C}$, UR de $70 \%$ e fotofase de 12 horas. O ensaio foi montado em delineamento de blocos ao acaso, com oito tratamentos e quinze repetiçôes.

As avaliações foram realizadas 24, 48 e 72 horas após a liberação dos pulgóes, pela contagem de ninfas e adultos, presentes em cada seçấo foliar. Nas duas primeiras avaliaçóes as ninfas foram retiradas com o auxílio de um pincel, deixando-se somente os adultos.

\section{Análise estatística}

Os dados antes da análise de variância foram transformados em $\sqrt{X+0,5}$. As médias foram comparadas pelo teste de Tukey $(\mathrm{p} \leq 0,05)$.

\section{RESULTADOS E DISCUSSÃO}

\section{Teste de biologia}

Os genótipos de tomateiro testados não influenciaram a duração do período pós-reprodutivo dos pulgóes (Tabela 2). No entanto, houve aumento na duraçáo do período ninfal, diminuição do período reprodutivo e da 
Tabela 2. Duração média ( \pm erro-padrão) dos períodos ninfal, reprodutivo e pós-reprodutivo; longevidade (dias) e número médio de ninfas de Myzus persicae sobre folíolos de genótipos de tomateiro com teores contrastantes de aleloquímicos, (Temperatura $25 \pm 2{ }^{\circ} \mathrm{C}$, Umidade relativa $70 \pm 10 \%$ e fotofase de 12 horas)

\begin{tabular}{lccccc} 
Genótipo & Ninfal & Reprodutivo & Pós-reprodutivo & Longevidade & $\begin{array}{c}\text { Número de ninfas/ } \\
\text { fêmea }\end{array}$ \\
\hline Débora Max & $6,6 \pm 0,40^{\mathrm{b}}$ & $8,2 \pm 0,36^{\mathrm{a}}$ & $1,0 \pm 0,22^{\mathrm{a}}$ & $9,2 \pm 0,41^{\mathrm{a}}$ & $16,4 \pm 1,03^{\mathrm{a}}$ \\
\hline Bravo F & $6,3 \pm 0,42^{\mathrm{b}}$ & $7,1 \pm 0,66^{\mathrm{ab}}$ & $0,7 \pm 0,21^{\mathrm{a}}$ & $7,7 \pm 0,81^{\mathrm{ab}}$ & $16,6 \pm 0,84^{\mathrm{a}}$ \\
\hline TOM-687 & $9,1 \pm 0,48^{\mathrm{a}}$ & $3,0 \pm 0,62^{\mathrm{c}}$ & $0,4 \pm 0,16^{\mathrm{a}}$ & $3,8 \pm 0,72^{\mathrm{c}}$ & $6,6 \pm 0,77^{\mathrm{b}}$ \\
\hline TOM-688 & $8,6 \pm 0,45^{\mathrm{a}}$ & $3,4 \pm 0,56^{\mathrm{c}}$ & $0,3 \pm 0,15^{\mathrm{a}}$ & $3,6 \pm 0,69^{\mathrm{c}}$ & $8,0 \pm 0,96^{\mathrm{b}}$ \\
\hline ZGB-703 & $6,8 \pm 0,32^{\mathrm{b}}$ & $8,6 \pm 0,40^{\mathrm{a}}$ & $0,6 \pm 0,16^{\mathrm{a}}$ & $9,2 \pm 0,49^{\mathrm{a}}$ & $15,9 \pm 1,31^{\mathrm{a}}$ \\
\hline ZGB-704 & $6,1 \pm 0,36^{\mathrm{b}}$ & $9,3 \pm 0,71^{\mathrm{a}}$ & $0,4 \pm 0,15^{\mathrm{a}}$ & $10,1 \pm 0,91^{\mathrm{a}}$ & $14,7 \pm 1,3^{\mathrm{a}}$ \\
\hline BPX-365G-899-07-04-02 & $6,5 \pm 0,43^{\mathrm{b}}$ & $5,1 \pm 0,87^{\mathrm{bc}}$ & $0,4 \pm 0,16^{\mathrm{a}}$ & $5,4 \pm 0,89^{\mathrm{bc}}$ & $8,5 \pm 1,07^{\mathrm{b}}$ \\
\hline BPX-367E-238-02 & $6,5 \pm 0,31^{\mathrm{b}}$ & $5,0 \pm 0,78^{\mathrm{bc}}$ & $0,3 \pm 0,15^{\mathrm{a}}$ & $5,4 \pm 0,98^{\mathrm{bc}}$ & $9,6 \pm 1,10^{\mathrm{b}}$ \\
\hline Média & $7,1 \pm 0,40$ & $6,2 \pm 0,62$ & $0,5 \pm 0,17$ & $6,8 \pm 0,73$ & $12,0 \pm 1,05$ \\
CV (\%) & 16,9 & 30,5 & 27,8 & 30,3 & 25,3
\end{tabular}

Médias seguidas pela mesma letra na coluna nẫo diferem significativamente entre si pelo teste Tukey $(\mathrm{p} \leq 0,05)$.

longevidade dos pulgóes mantidos nos genótipos com altos teores de acilaçúcares, quando comparados com as testemunhas Débora Max e Bravo $F_{1}$, bem como com as linhagens com altos teores de zingibereno. Nos genótipos com altos teores de 2-tridecanona ocorreu diminuição na duraçáo do período reprodutivo e da longevidade quando comparados com os genótipos com altos teores de zingibereno e com a testemunha comercial Débora Max, porém náo quando comparados com a testemunha Bravo $\mathrm{F}_{1}$ (Tabela 2). A produção de ninfas pelas fêmeas adultas foi significativamente menor nos genótipos com altos teores de acilaçúcares ou 2-tridecanona quando comparados com os genótipos com altos teores de zingibereno e com as testemunhas comerciais com baixos teores de aleloquímicos (Tabela 2).

Os genótipos de tomateiro com altos teores de acilaçucares ou 2-tridecanona mostraram-se significativamente mais eficientes em provocar efeitos negativos no desenvolvimento do pulgão $M$. persicae, o que indica que podem conferir graus de resistência do tipo antibiose. Contudo, não provocaram a morte dos pulgôes durante a fase ninfal como observado em outro trabalho em que foi avaliado o grau de resistência a $M$. persicae das mesmas espécies silvestres que deram origem as linhagens melhoradas, avaliadas no presente trabalho (Simmons et al., 2003) o que pode ser reflexo do maior teor de aleloquímicos presentes nas espécies silvestres relativamente aos presentes nas linhagens melhoradas usadas no presente ensaio.

LeITE et al. (1999b) observaram, da mesma forma como nesta pesquisa, a diminuiçáo da longevidade e produçấo de ninfas do pulgão $M$. persicae quando mantidos sobre plantas do acesso silvestre de tomateiro S. habrochaites var. glabratum ('PI-134417'), quando comparado com insetos mantidos sobre o tomateiro domesticado.

Seis acessos silvestres de $S$. habrochaites, três de $S$. pennellii e uma cultivar comercial de tomate (testemunha) foram avaliados por Simmons et al. (2003) quanto ao nível de resistência do tipo antibiose ao pulgão
M. persicae. Os autores verificaram que todos os acessos silvestres foram mais resistentes ao pulgáo quando comparados a testemunha, porém os acessos 'LA-716', 'LA-1724' e 'PI-473422' todos da espécie S. pennellii apresentaram um maior nível de resistência a esse afídeo. Assim como híbridos $\mathrm{F}_{1}$, obtidos do cruzamento do tomateiro domesticado com a espécie silvestre $S$. pennellii, também afetaram negativamente o desenvolvimento biológico de pulgóes $M$. persicae confinados sobre a face adaxial dos folíolos das plantas (Simmons et al., 2005). Esses resultados concordam com o encontrado no presente trabalho, o que evidencia o maior nível de resistência do tipo antibiose dos genótipos oriundos do cruzamento do tomateiro domesticado com a espécie silvestre $S$. pennelii.

RESENDE et al. (2009), assim como neste trabalho, observaram efeito adverso de genótipos com altos teores de acilaçúcares no desenvolvimento biológico da mosca branca Bemisia tabaci biótipo B, que como o M. persicae também é um inseto pertencente a ordem Hemiptera. Apesar do número de ovos desse inseto tenha sido elevado em alguns dos genótipos selecionados com altos teores de acilaçúcares, o número de ninfas que sobreviveram foi reduzido, evidenciando ocorrência da antibiose.

No presente trabalho, os genótipos com altos teores do aleloquímico zingibereno não afetaram o desenvolvimento do pulgão $M$. persicae. O contrário se registrou com a mosca branca $B$. argentifolii, que segundo SiLva et al. (2009), altos teores de zingibereno foram efetivos no sentido de reduzir a sobrevivência de ninfas desse inseto-praga.

\section{Teste de não preferência com chance de escolha para pulgões alados}

Não houve diferença significativa entre os tratamentos, no comportamento dos pulgóes alados em teste de livre escolha, após 72 horas da liberação (Tabela 3). 
As espécies silvestres $S$. pennellii, $S$. habrochaites var. hirsutum e $S$. harbrochaites var. glabratum, afetam o comportamento de seleção hospedeira da mosca branca $B$. argentifolii, sendo menos preferidas por este inseto para oviposição (Liedi et al., 1995; Muigai et al., 2002). $\mathrm{Na}$ espécie $S$. pennellii a diminuição da oviposição por $B$. argentifolii está associada com a maior quantidade de tricomas do tipo IV, (presumivelmente rico em acilaçúcares) presentes nesta espécie selvagem (LiEDi et al., 1995). Provavelmente, a concentração de aleloquímicos presentes nas linhagens de tomateiro melhoradas usadas no presente ensaio não tenha sido suficiente para provocar efeito de não preferência nos pulgóes alados $M$. persicae durante o processo de seleção hospedeira, pois a concentração de aleloquímicos é maior nas espécies silvestres de tomateiro que deram origem as linhagens testadas neste trabalho (Silva et al., 2009).

\section{Teste de não preferência com chance de escolha para pulgões ápteros}

Não foram observadas diferenças significativas entre os tratamentos no comportamento do pulgão áptero, em teste de livre escolha, em todas as avaliaçóes realizadas (Tabelas 4 e 5).

Assim como ocorreu no teste de não preferência para pulgóes alados, os genótipos de tomateiro com altos teores de aleloquímicos, que são linhagens melhoradas, também não provocaram efeitos adversos no comportamento do pulgão áptero. Isto pode ser devido a menor concentração do aleloquímico nos folíolos das linhagens (Silva et al., 2009), quando comparado com a concentração presente nos folíolos das espécies silvestres S. pennellii, S. habrochaites var. hirsutum e S. harbrochaites var. glabratum, em que o teor de aleloquímicos é maior, e que apresentam resistência a $M$. persicae do tipo não preferência (Simmons et al., 2003).

Resultados contrastantes aos observados neste trabalho foram constatados por Simmons et al. (2005) que, ao avaliarem híbridos $\mathrm{F}_{1}$ obtidos a partir do cruzamento do tomateiro domesticado (S. lycopersicum) com os acessos selvagens (S pennellii) LA-716' e (S. galapagense) 'LA-1410', observaram que esses genótipos foram menos preferidos por ninfas de $M$. persicae quando comparados com o tomateiro domesticado com baixos teores de aleloquímicos.

As mesmas linhagens com altos teores de acilaçúcares ou zingibereno avaliadas nesta pesquisa, em outro trabalho (Silva et al., 2009), foram menos preferidas pela mosca branca $B$. argentifolii para oviposição, em teste livre de escolha.

Os resultados encontrados no presente trabalho mostram o potencial que os genótipos (linhagens) com altos teores dos aleloquímicos: acilaçúcares e 2-tridecanona
Tabela 3. Média ( \pm erro-padrão) do número de ninfas e adultos alados de Myzus persicae presentes em diferentes genótipos de tomateiro com teores contrastantes de aleloquímicos nas folhas, 72 horas após a liberação (Temperatura $25 \pm 2{ }^{\circ} \mathrm{C}$, Umidade relativa $70 \pm 10 \%$ e fotofase de 12 horas).

\begin{tabular}{|lrc|}
\hline Genótipo & \multicolumn{1}{c}{ Ninfas } & Adultos alados \\
\hline Débora Max & $7,14 \pm 2,36^{\mathrm{a}}$ & $1,71 \pm 0,60^{\mathrm{a}}$ \\
\hline Bravo $\mathrm{F}_{1}$ & $15,71 \pm 5,21^{\mathrm{a}}$ & $2,58 \pm 0,94^{\mathrm{a}}$ \\
\hline TOM-687 & $10,42 \pm 2,74^{\mathrm{a}}$ & $1,00 \pm 0,37^{\mathrm{a}}$ \\
\hline TOM-688 & $9,14 \pm 1,98^{\mathrm{a}}$ & $0,71 \pm 1,71^{\mathrm{a}}$ \\
\hline ZGB-703 & $10,71 \pm 2,76^{\mathrm{a}}$ & $2,00 \pm 0,69^{\mathrm{a}}$ \\
\hline ZBB-704 & $13,00 \pm 2,45^{\mathrm{a}}$ & $2,28 \pm 0,52^{\mathrm{a}}$ \\
\hline BPX-365G-899-07-04-02 & $3,71 \pm 1,61^{\mathrm{a}}$ & $0,42 \pm 0,29^{\mathrm{a}}$ \\
\hline BPX-367E-238-02 & $13,57 \pm 6,39^{\mathrm{a}}$ & $1,85 \pm 0,55^{\mathrm{a}}$ \\
\hline Média & $10,42 \pm 3,19$ & $1,57 \pm 0,71$ \\
\hline CV(\%) & 37,9 & 38,8 \\
\hline
\end{tabular}

Médias seguidas pela mesma letra na coluna não diferem significativamente entre si pelo teste Tukey $(\mathrm{p} \leq 0,05)$

Tabela 4. Número médio ( \pm erro-padrão) de ninfas de Myzus persicae em folíolos de genótipos de tomateiro com teores contrastantes de aleloquímicos nas folhas, 24, 48 e 72 horas após a liberação dos pulgóes (Temperatura $25 \pm 2{ }^{\circ} \mathrm{C}$, Umidade relativa $70 \pm 10 \%$ e fotofase de 12 horas)

\begin{tabular}{lccc} 
Genótipo & $\mathbf{2 4} \mathbf{h}$ & $\mathbf{4 8} \mathbf{~ h}$ & $\mathbf{7 2} \mathbf{~ h}$ \\
\hline Débora Max & $3,73 \pm 0,84^{\mathrm{a}}$ & $5,13 \pm 1,08^{\mathrm{a}}$ & $4,60 \pm 0,85^{\mathrm{a}}$ \\
\hline Bravo & $5,86 \pm 1,25^{\mathrm{a}}$ & $9,13 \pm 1,37^{\mathrm{a}}$ & $5,86 \pm 0,69^{\mathrm{a}}$ \\
\hline TOM-687 & $4,93 \pm 1,11^{\mathrm{a}}$ & $7,00 \pm 1,25^{\mathrm{a}}$ & $6,20 \pm 0,94^{\mathrm{a}}$ \\
\hline TOM-688 & $3,13 \pm 0,65^{\mathrm{a}}$ & $5,73 \pm 0,97^{\mathrm{a}}$ & $5,53 \pm 0,75^{\mathrm{a}}$ \\
\hline ZGB-703 & $5,13 \pm 1,77^{\mathrm{a}}$ & $5,13 \pm 1,38^{\mathrm{a}}$ & $4,93 \pm 1,12^{\mathrm{a}}$ \\
\hline ZGB-704 & $4,80 \pm 1,25^{\mathrm{a}}$ & $6,53 \pm 1,12^{\mathrm{a}}$ & $4,40 \pm 1,08^{\mathrm{a}}$ \\
\hline BPX-365G-899-07-04-02 & $4,93 \pm 1,26^{\mathrm{a}}$ & $6,33 \pm 1,18^{\mathrm{a}}$ & $3,53 \pm 0,70^{\mathrm{a}}$ \\
\hline BPX-367E-238-02 & $4,00 \pm 0,82^{\mathrm{a}}$ & $7,06 \pm 0,93^{\mathrm{a}}$ & $6,06 \pm 1,39^{\mathrm{a}}$ \\
\hline Média & $4,56 \pm 1,12$ & $6,50 \pm 1,16$ & $5,13 \pm 0,94$ \\
\hline CV (\%) & 44,9 & 38,1 & 34,9
\end{tabular}

Médias seguidas pela mesma letra na coluna nâo diferem significativamente entre si pelo teste Tukey $(\mathrm{p} \leq 0,05)$.

Tabela 5. Número médio ( \pm erro-padrão) de adultos de Myzus persicae em folíolos de genótipos de tomateiro com teores contrastantes de aleloquímicos nas folhas, 24, 48 e 72 horas após a liberação dos pulgóes (Temperatura $25 \pm 2{ }^{\circ} \mathrm{C}$, Umidade relativa $70 \pm 10 \%$ e fotofase de $12 \mathrm{~h}$ ).

\begin{tabular}{lccc} 
Genótipo & $\mathbf{2 4} \mathbf{h}$ & $\mathbf{4 8} \mathbf{~ h}$ & $\mathbf{7 2} \mathbf{~ h}$ \\
\hline Débora Max & $2,73 \pm 0,45^{\mathrm{a}}$ & $2,40 \pm 0,37^{\mathrm{a}}$ & $2,46 \pm 0,53^{\mathrm{a}}$ \\
\hline Bravo & $4,33 \pm 0,67^{\mathrm{a}}$ & $3,80 \pm 0,53^{\mathrm{a}}$ & $2,80 \pm 0,45^{\mathrm{a}}$ \\
\hline TOM-687 & $3,00 \pm 0,42^{\mathrm{a}}$ & $3,06 \pm 0,54^{\mathrm{a}}$ & $3,66 \pm 0,54^{\mathrm{a}}$ \\
\hline TOM-688 & $2,33 \pm 0,33^{\mathrm{a}}$ & $2,80 \pm 0,51^{\mathrm{a}}$ & $2,66 \pm 0,34^{\mathrm{a}}$ \\
\hline ZGB-703 & $2,93 \pm 0,58^{\mathrm{a}}$ & $2,86 \pm 0,63^{\mathrm{a}}$ & $3,53 \pm 1,56^{\mathrm{a}}$ \\
\hline ZGB-704 & $3,06 \pm 0,57^{\mathrm{a}}$ & $3,40 \pm 0,54^{\mathrm{a}}$ & $1,40 \pm 0,34^{\mathrm{a}}$ \\
\hline BPX-365G-899-07-04-02 & $2,53 \pm 0,53^{\mathrm{a}}$ & $2,66 \pm 0,51^{\mathrm{a}}$ & $1,93 \pm 0,50^{\mathrm{a}}$ \\
\hline BPX-367E-238-02 & $2,80 \pm 0,36^{\mathrm{a}}$ & $3,26 \pm 0,31^{\mathrm{a}}$ & $3,06 \pm 0,53^{\mathrm{a}}$ \\
\hline Média & $2,96 \pm 0,49$ & $2,78 \pm 0,49$ & $2,68 \pm 0,59$ \\
\hline CV (\%) & 31,8 & 30,8 & 34,9
\end{tabular}

Médias seguidas pela mesma letra na coluna não diferem significativamente entre si pelo teste Tukey $(\mathrm{p} \leq 0,05)$. 
possuem como fonte de resistência na obtençáo de cultivares/híbridos comerciais resistentes ao pulgão $M$. persicae nos programas de melhoramento genético do tomateiro, e para posteriormente serem usados pelos produtores, juntamente com outras táticas de controle no manejo integrado de pragas da cultura.

\section{CONCLUSÃO}

As linhagens TOM-687 e TOM-688, com altos teores de acilaçúcares e as linhagens BPX-365G-899-07-04-02 e BPX-367E-238-02 com altos teores de 2-tridecanona apresentam resistência do tipo antibiose ao pulgão $M$. persicae.

\section{AGRADECIMENTOS}

À Fundação de Amparo à Pesquisa do Estado de Minas Gerais (FAPEMIG), ao Conselho Nacional de Desenvolvimento Científico e Tecnológico (CNPq), à Coordenação de Aperfeiçoamento de Pessoal de Nível Superior (CAPES), à Universidade Federal de Lavras (UFLA), à Fundação de Apoio ao Ensino, Pesquisa e Extensão (FAEPE), à Fundação de Desenvolvimento Científico e Cultural (FUNDECC) e à Hortiagro Sementes, pelo apoio recebido.

\section{REFERÊNCIAS}

ANTTONELLI, M.; ARPAIA, S.; CELLINI, F.; D'AMBROSIO, C.; GRIECO, P.; VANADIA, S. Effetti del CMV in Basilicata um programma per La difesa del pomodoro. Inflore Fitopatloligia, v.42, p.51-55, 1992.

ARAGÃO, C.A.; CARDOSO, M.G.; MALUF, W.R.; DANTAS, B.F. Método colorimétrico para determinação de 2-tridecanona (2-TD) em folíolos de tomateiro. Ciência e Agrotecnologia, v.24, p.105-109, 2000.

AZEVEDO, S.M.; FARIA, M.V.; MALUF, W.R.; OLIVEIRA, A.C.B.; FREITAS, J.A. Zingiberene-mediated resistance to the South American tomato pinworm derived from Lycopersicum hirsutum var. hirsutum. Euphytica, v.134, p.347-351, 2003.

CARTER, C.D.; SACALIS, J.N.; GIANFAGNA, T.J. Resistance to Colorado Potato Beetle in relation to zingiberene content of Lycopersicum species. Report of Tomato Genetics Cooperative, v.38, p.11-12, 1988.

FILGUEIRA, F.A.R. Tomate: Produção em campo, em casa-devegetação e em hidroponia. Lavras: Ed. UFLA, 2004. 400p.

FREITAS, J.A.; MALUF, W.R.; CARDOSO, M.G.; GOMES, L.A.A.; BEARZOTTI, E. Inheritance of foliar zingiberene contents and their relationship to trichome densities and whitefly resistance in tomatoes. Euphytica, v.127, p.275-287, 2002. DOI: 10.1023/A: 1020239512598
GIANFAGNA, T.J.; CARTER, C.D.; SACALIS, J.N. Temperature and photoperiod influence trichome density and sesquiterpene content of Lycopersicum hirsutum f. hirsutum. Plant Physiology, v.100, p.1403-1405, 1992. DOI: 10.1104/pp.100.3.1403

GOFFREDA, J.C.; MUTSHLER, M.A.; AVÉ, D.A.; TINGEY, W.M.; STEFFENS, J.C. Aphid deterrence by glucose esters in glandular trichome exudate of wild tomato, Lycopersicon pennellii. Journal of Chemical Ecology, v.15, p.2137-2147, 1989. DOI: 10.1007/BF01207444

GONÇALVES NETO, A.C.; SILVA V.F.; MALUF W.R.; MACIEL G.M; NÍZIO, D.A.C.; GOMES L.A.A.; AZEVEDO S.M. Resistência à traça-do-tomateiro em plantas com altos teores de acilaçúcares nas folhas. Horticultura Brasileira, v.28, p.203-208, 2010. DOI: 10.1590/S0102-05362010000200011

GONÇALVES, L.D.; MALUF, W.R.; CARDOSO, M.G.; RESENDE, J.T.V.; CASTRO, E.M.; SANTOS, N.M.; NASCIMENTO, I.R.; FARIA, M.V. Relação entre zingibereno, tricomas foliares e repelência de tomateiros a Tetranychus evansi. Pesquisa Agropecuária Brasileira, v.41, p.267-273, 2006. DOI: 10.1590/S0100-204X2006000200011

GONÇALVES, M.I.F; MALUF, W.R.; GOMES, L.A.A.; BARBOSA, L.V. Variation of 2-tridecanone level in tomato plant leaflets and resistance to two mite species (Tetranychus sp.). Euphytica, v.104, p.33-38, 1998.

JUVIK, J.; BABKA, B.; TIMMERMANN, E. Influence of trichome exudates from species of Lycopersicon on oviposition behavior of Heliothis zea Boddie. Journal of Chemical Ecology, v.14, p.1261-1287, 1988.

LEITE, G.L.D. Resistência do tomate a pragas. Unimontes Científica, v.6, p.129-140, 2004.

LEITE, G.L.D.; PICANÇO, M.; AZEVEDO, A.A.; GONRING, A.H.R. Efeito de tricomas, aleloquímicos e nutrientes na resistência de Lycopersicon hirsutum à traça-do-tomateiro. Pesquisa Agropecuária Brasileira, v.34, p.2059-2064, 1999a. DOI: 10.1590/ S0100-204X1999001100012

LEITE, G.L.D.; PICANÇO, M.; GUEDES, R.N.C.; SKOWRONSKI, L. Effect of fertilization levels, age and canopy height of Lycopersicon hirsutum on the resistance to Myzus persicae. Entomologia Experimentalis et Applicata, v.91, p.267-273, 1999b.

LIEDL, E.; LAWSON, D.M.; WHITE, K.K. SHAPIRO, J.A.; COHEN, D.E.; CARSON, W.G.; TRUMBLE, J.T.; MUTSCHLER, M.A. Acylsugars of wild tomato Lycopersicon pennellii alters settling and reduces oviposition of Bemisia argentifolii (Homoptera: Aleyrodidae). Journal of Economic Entomology, v.88, p.742-748, 1995.

MALUF, W.R.; INOUE, I.F.; FERREIRA, R.P.D.; GOMES, L.A.A.; CASTRO, E.M.; CARDOSO, M.G. Higher glandular trichome density in tomato leaflets and repellence to spider mites. Pesquisa Agropecuária Brasileira, v.49, p.1227-1235, 2007. DOI: 10.1590/S0100-204X2007000900003

MALUF, W.R.; SILVA, V.F.; CARDOSO, M.G.; GONÇALVES NETO, A.C.; MACIEL, G.M.; NÍZIO, D.A.C. Resistance to the 
South American tomato pinworm Tuta absoluta in high acylsugar and/or high zingiberene tomato genotypes. Euphytica, v.176, p.113-123, 2010. DOI: 10.1007/s10681-010-0234-8

MALUF, W.R.; CAMPOS, G.A.; CARDOSO, M.G. Relationships between trichome types and spider mite (Tetranychus evansi) repellence in tomatoes with respect to foliar zingiberene contents. Euphytica, v.121,p.73-80, 2001.DOI: 10.1023/A:1012067505361

MUIGAI, S.G.; SCHUSTER, D.J.; SNYDER, J.C.; SCOTT, J.W.; BASSETT, M.J.; MCAUSLANE, H.J. Mechanisms of resistance in Lycopersicon germplasm to the whitefly Bemisia argentifolii. Phytoparasitica, v.30, p.347-360, 2002.

PANDA, N.; KRUSH, G.S. Host plant resistance to pest. Guildford: Biddles, 1995. 431p.

PERALTA, I.E.; KNAPP, S.; SPOONER, D.M. New species of wild tomatoes (Solanum Section Lycopersicon: Solanaceae) from northern Peru. Systematic Botany, v.30, p.424-434, 2005. DOI: $10.1600 / 0363644054223657$

PEREIRA, G.V.N.; MALUF, W.R.; SANTOS, C.D.; GONÇALVES, L.D.; NASCIMENTO, I.R.; GOMES, L.A.A.; LICURSI, V. Seleção para alto teor de acilaçúcares em genótipos de tomateiro e sua relação com a resistência ao ácaro vermelho (Tetranychus evansi) e a traça (Tuta absoluta). Ciência e Agrotecnologia, v.32, p.996-1004, 2008. DOI: 10.1590/S141370542008000300045

RESENDE, J.T.V.; MALUF, W.R.; FARIA, M.V.; PFANN, A.Z.; NASCIMENTO, I.R. Acylsugars in tomato leaflets confer resistance to the South American tomato pinworm, Tuta absoluta Meyr. Scientia Agricola, v.63, p.20-25, 2006. DOI: 10.1590/ S0103-90162006000100004
RESENDE, J.T.V.; CARDOSO, M.G.; MALUF, W.R.; SANTOS, C.D.; GONÇALVES, L.D.; RESENDE, L.V.; NAVES, F.O. Método colorimétrico para quantificação de acilaçúcar em genótipos de tomateiro. Ciência e Agrotecnologia, v.26, p.12041208,2002

RESENDE, J.T.V.; MALUF, W.R.; CARDOSO, M.G.; GONÇALVES, L.D.; FARIA, M.V.; NASCIMENTO, I.R. Resistance of tomato genotypes to the silverleaf whitefly mediated by acylsugars. Horticultura Brasileira, v.27, p.345-348, 2009. DOI: 10.1590/S0102-05362009000300015

SILVA, V.F.; MALUF, W.R.; CARDOSO, M.G.; GONÇALVES NETO, A.C.; MACIEL, G.M.; NÍZIO, D.A.C.; SILVA, V.A. Resistência mediada por aleloquímicos de genótipos de tomateiro à mosca-branca e ao ácaro-rajado. Pesquisa Agropecuária Brasileira, v.44, p.1262-1269, 2009. DOI: 10.1590/S0100204X2009001000008

SIMMONS, A.T.; GURR, G.M.; MCGRATH, D.; NICOL, H.I.; MARTIN, P.M. Trichomes of Lycopersicon spp. and their effect on Myzus persicae (Sulzer) (Hemiptera: Aphididae). Australian Journal of Entomology, v.42, p.373-378, 2003. DOI: $10.1046 / \mathrm{j} .1440-$ 6055.2003.00376.x

SIMMONS, A.T.; MCGRATH, D.; GURR, G.M. Trichome characteristics of $\mathrm{F}_{1}$ Lycopersicon esculentum $\mathrm{x} L$. cheesmanii $\mathrm{f}$. minor and L. esculentum $\mathrm{x}$ L. pennellii hybrids and effects on Myzus persicae. Euphytica, v.144, p.313-320, 2005. DOI: 10.1007/ s10681-005-8002-x

SUINAGA, F.A.; CASALI, V.W.D.; SILVA, D.J.H.; PICANÇO, M.C. Dissimilaridade genética de fontes de resistência de Lycopersicon spp. a Tuta absoluta (Meyrick, 1917) (Lepidoptera: Gelechiidae). Revista Brasileira de Agrociência, v.9, p.371-376, 2003. 